\title{
O poder da palavra: a habilidade retórica de Simão Pereira De Sá Na Crônica Historia Topografica e Belica da Nova Colonia do Sacramento e a sua influência na manutenção dessa praça e na historiografia brasileira contemporânea
}

Tamyres Gonçalves Palma Zimmer ${ }^{1}$ Orientadora: Prof ${ }^{\mathrm{a}} \mathrm{Dr}^{\mathrm{a}}$. Martha Daisson Hameister

O presente trabalho analisará o discurso construído por Simão Pereira de Sá em sua obra Historia Topografica e Belica da Nova Colonia do Sacramento do Rio da Prata, escrita por encomenda de Gomes Freire de Andrade, governador do Rio de Janeiro e da Repartição Sul. Embora a datação da obra seja incerta, Capistrano de Abreu delimita um recorte temporal na qual a confecção da obra possivelmente se encontra, sendo "depois de setembro de 1737 [...] e anterior a 1750"2. Mesmo que a escrita da obra provavelmente se encontre no segundo quartel do século XVIII, Simão Pereira de Sá incorpora diversos relatos anteriores ao período em que redigiu seu texto, voltando-se às primeiras tentativas de povoação da Colônia do Sacramento em 1680 e entre 1681-1715.

Como o intuito na elaboração desta obra era o de convencimento da Coroa portuguesa em lutar pela posse da Colônia do

\footnotetext{
${ }^{1}$ Graduada em História pela Universidade Federal do Paraná.

${ }^{2}$ ABREU, Capistrano apud MARQUES, Viviane Sueli. Edição semidiplomática de História topográfica e bélica da Nova Colonia do Sacramento do Rio da Prata, códice 677, da Biblioteca Nacional de Lisboa. (Dissertação de Mestrado). São Paulo, USP, 2008, 216p. p. 17.
} 
Sacramento, a escrita da crônica consequentemente deveria agradar ao Gomes Freire de Andrade, que era um defensor ferrenho da manutenção da Colônia. A partir desta necessidade, vemos a exaltação constante da Colônia por parte do Pereira de Sá, onde o autor chega a comparar a Colônia do Sacramento a "outra Cartago, fatigando a todos com os rebates continuos, sem que das mãos depuzessem as armas"3.

Buscarei neste trabalho analisar de maneira crítica a escrita do cronista, que devido aos interesses por trás da escrita e encomenda da crônica por parte de Gomes Freire de Andrade, desenvolveu um conteúdo muito apaixonado, e que por vezes tem como função exaltar as qualidades portuguesas em detrimento dos castelhanos, sempre descritos como inferiores aos portugueses em qualidades, e por vezes até no comportamento cristão. A argumentação de Simão Pereira de Sá, quando tende a demonstrar como os portugueses eram melhores que os castelhanos inclusive no comportamento cristão, dá margem à interpretação de que ele busca, através do "bom comportamento português", justificar que o avanço territorial deles é mais benéfico que o avanço castelhano, pois uma das missões dos ibéricos - tanto portugueses quanto espanhóis - na América era promover o avanço do catolicismo entre os indígenas. Pereira de Sá tenta demonstrar que devido a essa missão e ao comportamento cristão superior dos

3 SÁ, Simão Pereira de. Historia Topografica e Belica da Nova Colonia do Sacramento do Rio da Prata, Escrita por Ordem do Governador e Capitão Geral do Rio de Janeiro em 1737 e 1777. Porto Alegre: Arcano 17, 1993. p. 15. 
portugueses, era melhor que os espanhóis saíssem destas terras para bons cristãos - os portugueses - as povoarem.

Para tanto, farei uso da obra Tratado da argumentação: A Nova Retórica, de Chain Perelman e Lucie Olbrechts-Tyteca ${ }^{4}$, com o qual realizarei uma análise retórica da obra de Pereira de Sá. Através dela buscarei definir o auditório do autor, ou seja, para quem ele escreve e os recursos utilizados para consolidar sua argumentação, tais como a repetição, a demonstração, a adjetivação, analogias, etc. A definição do "auditório" sugerido por Perelman e Olbrechts-Tyteca é fundamental para compreendermos em que contexto e projeto políticoadministrativo se insere a escrita da crônica por Pereira de Sá. Por auditório podemos compreender para quem os argumentos de convencimento são lançados e depois esboçar uma delimitação - caso haja - dos apoiadores e dos oponentes da ideia-chave de defesa e manutenção da praça da Colônia do Sacramento, o que pode ser determinante na construção do texto do autor. Tem-se aqui, portanto, um princípio teórico e metodológico que norteará a investigação.

A obra de Simão Pereira de Sá é dividida em três livros, sendo que cada um deles relata um período do povoamento português na Colônia do Sacramento. O primeiro livro narra o breve período de povoamento em 1680, data de sua fundação pelos portugueses a mando de D. Pedro II. A necessidade de um porto de comércio e de expansão

\footnotetext{
${ }^{4}$ PERELMAN, Chaim; OLBRECHTS-TYTECA, Lucie. Tratado de argumentação: a nova retórica. tradução: Maria Ermantina de Almeida Prado Galvão; revisão da tradução: Eduardo Brandão. 2. ed. São Paulo: Martins Fontes, 2005. (Justiça e direito).
} 
territorial levou os portugueses a fundarem a Colônia na margem esquerda do Rio da Prata, praticamente em frente a Buenos Aires, para servir como acesso aos mercados de Buenos Aires, Paraguai e Alto Peru - mercados estes negligenciados pela Coroa Hispânica ${ }^{5}$ - além de facilitar o acesso à prata do Alto Peru, essencial para a economia das colônias e das metrópoles no período.

O avanço para o extremo sul da colônia portuguesa servia tanto aos interesses da Coroa Portuguesa quanto de particulares, principalmente da elite fluminense. Este avanço era "estimulado pela Coroa e levado à cabo com a ação, apoio e interesses de particulares e autoridades locais" 6 . Para a Coroa portuguesa, Sacramento tinha "a finalidade de restabelecer no comércio Atlântico Português a carreira Rio da Prata - Rio de Janeiro - Luanda, onde a primeira era fonte de metais, nomeadamente a prata, tão necessária à economia do centro da Colônia"7, carreira esta que foi muito utilizada durante o período da União Ibérica para optimizar e expandir o tráfico negreiro.

O segundo período narrado por Sá vai de 1681 a 1705, encerrado com um cerco castelhano a Sacramento que durou mais de um ano, e que foi findado, segundo Simão Pereira, quando o resgate

\footnotetext{
${ }^{5}$ PRADO, Fabrício. Colônia do Sacramento: O Extremo Sul da América Portuguesa. Porto Alegre: Editora Prefeitura Municipal de Porto Alegre, 2002. p. 18.

${ }^{6}$ PRADO, Fabrício. Colônia do Sacramento: O Extremo Sul da América Portuguesa. Porto Alegre: Editora Prefeitura Municipal de Porto Alegre, 2002. p. 21.

${ }^{7}$ Idem, Ibidem. p. 39.
} 
português chegou e foram socorridos os portugueses isolados dentro das muralhas. O último período narrado por Sá vai do ano de 1716 a 1737.

O último relato de Simão é bem mais longo e completo, o que dá margens para acreditarmos que pelo menos este relato possa ter sido feito a partir de uma vivência in loco, diferente dos dois primeiros, que são mais curtos e provavelmente baseados em relatos colhidos à época. Em seu Livro III, Simão Pereira de Sá privilegia principalmente a narrativa dos dois últimos anos da ocupação, período em que a Colônia do Sacramento esteve isolada devido ao cerco imposto pelos castelhanos aos portugueses.

No primeiro capítulo da monografia apresento uma introdução sobre o autor e obra por mim analisada ao longo de toda essa investigação, buscando contextualizar os mesmos para facilitar a compreensão das técnicas de escrita e motivações do autor por trás da obra. Trato também sobre o acesso português à região do Rio da Prata e os eventos que levaram Portugal a se interessar pela região do Rio da Prata a partir da União Ibérica entre Portugal e Castela, e como após o rompimento da mesma, tanto a Coroa portuguesa quanto os lusobrasílicos mantiveram um grande interesse voltado para a região do Prata, tanto por ser um ótimo porto natural como porta de acesso à prata hispânica, além de como esta expansão ao sul foi efetivada pela ação principalmente - da elite fluminense, maior interessada em manter o lucrativo comércio que havia encontrado na região do Rio da Prata. 
Apresento ainda uma breve discussão conceitual em que se busca determinar qual nomenclatura deveria ser empregada no trato à Colônia, pois a mesma foi uma empresa lusa sem precedentes, única em sua execução e funções. Como Sacramento aparece nos documentos da época referida como praça, vila ou cidade, Fabrício Prado apresenta em seu estudo as diferentes características administrativas que cada um destes núcleos urbanos possuía, a fim de posicionar Sacramento em seu devido lugar, e ao final de sua exposição argumentativa chega à conclusão que de fato Sacramento foi tão única que qualquer denominação possível de empresa lusa a ser empregada não englobaria sua complexidade.

Por fim, apresento um panorama geral sobre o início efetivo da colonização lusa à Colônia do Sacramento e como esta se desenvolveu ao longo dos anos e das tomadas castelhanas e retomadas portuguesas.

No segundo capítulo da monografia selecionei, a partir de critérios por mim explanados ao início do mesmo capítulo, trabalhos de diferentes tipologias para analisar a maneira como a Colônia do Sacramento é tratada - ou não - na historiografia nacional. Há obras da historiografia nacionalista e tradicionalista de autores membros do IHGB $^{8}$ e do IHGRGS $^{9}$, trabalhos acadêmicos, livros paradidáticos e livros didáticos de ensino fundamental e médio.

\footnotetext{
${ }^{8}$ Instituto Histórico e Geográfico Brasileiro.

${ }^{9}$ Instituto Histórico e Geográfico do Rio Grande do Sul.
} 
A partir de minha seleção ${ }^{10}$, busquei perceber como a Colônia do Sacramento é tratada por cada ramo da produção historiográfica. Em Fronteira, de Moysés Vellinho, e em A Historiografia Rio-grandense, de Ieda Gutfreind, vemos um "ranço" por este território que foi perdido aos castelhanos fazer parte da nossa história. Em Capítulos da História Colonial: 1500 - 1800, de Capistrano de Abreu, vemos o total desprezo pelo território e pelos homens que lá estiveram. Segundo o autor, o tal "ninho, antes de contrabandistas que de soldados"11 foi um local infrutífero aos interesses portugueses e mal administrado, pois, segundo o autor afirma, nas palavras de algum cronista da época, para se povoar uma região, é necessário casais, o que, segundo Capistrano, não houve em Sacramento. Antes, ali deu espaço ao surgimento do gaúcho, do gaudério, a "prole sinistra"12 que atormentava a margem esquerda do Rio da Prata. Em outras obras vemos que o território é claramente desmerecido por ter se tornado território castelhano, mas os homens que lá trabalharam e lutaram são vistos como verdadeiros

${ }^{10}$ Vellinho, Moysés. Fronteira. Porto Alegre: Editora Globo, 1975; GUTFREIND, Ieda. A Historiografia Rio-Grandense. 2. ed. Porto Alegre: Ed. Universidade/UFRGS, 1998; ABREU, Capistrano de. Capítulos da História Colonial: 1500 - 1800. Brasília: Conselho Editorial do Senado Federal, 1998; SPALDING, Walter. Gênese do BrasilSul. Porto Alegre: Livraria Sulina Editora, 1953; SPALDING, Walter. Construtores do Rio Grande. Porto Alegre: Livraria Sulina Editora, 1969 (3 volumes); SILVA, Riograndinho Costa e. Notas à Margem da História do Rio Grande do Sul. Porto Alegre: Editora Globo, 1968; DOMINGUES, Moacyr. A Colônia do Sacramento e o sul do Brasil. Porto Alegre: Sulina, 1973.

11 ABREU, Capistrano de. Capítulos da História Colonial: 1500 - 1800. Brasília: Conselho Editorial do Senado Federal, 1998. p. 186.

12 ABREU, Capistrano de. Capítulos da História Colonial: 1500 - 1800. Brasília: Conselho Editorial do Senado Federal, 1998. p. 186. 
heróis, que tentaram expandir o território luso, e conseguiram, pois conquistaram o território do continente de São Pedro, tomando inclusive o território dos Sete Povos das Missões para o rei português, como nos escritos de Walter Spalding por mim selecionados ${ }^{13}$.

Por fim, analiso obras ${ }^{14}$ que fizeram uso da crônica de Simão Pereira de Sá como detentora da verdade, de maneira acrítica, confiando nas palavras daquele erudito sem se perguntar quais seriam os interesses por trás de sua retórica. Entre elas estão o livro "Colônia do Sacramento: O Extremo Sul da América Portuguesa" de Fabrício Prado, a tese de mestrado de Martha Daisson Hameister intitulada " $O$ continente do Rio Grande de São Pedro: os homens, suas redes de relação e suas mercadorias semoventes (c. 1727-c. 1763)", um artigo da mesma autora de título "No princípio era o caos: a formação de um povoado na fronteira americana dos Impérios Ibéricos através do estudo das relações de compadrio" e a tese de mestrado de Viviane Sueli Marques intitulada "Edição semidiplomática de História topográfica e

\footnotetext{
${ }^{13}$ Gênese do Brasil-Sul (1953) e Construtores do Rio Grande (1969).

${ }^{14}$ PRADO, Fabrício. Colônia do Sacramento: o Extremo Sul da América Portuguesa. Porto Alegre: Editora Prefeitura Municipal de Porto Alegre, 2002; HAMEISTER, Martha Daisson. O continente do Rio Grande de São Pedro: os homens, suas redes de relações e suas mercadorias semoventes (c. 1727-c. 1763); HAMEISTER, Martha Daisson. No princípio era o caos: a formação de um povoado na fronteira americana dos Impérios Ibéricos através do estudo das relações de compadrio. Revista de História Regional. v. 15, 2010; MARQUES, Viviane Sueli. Edição semidiplomática de História topográfica e bélica da Nova Colônia do Sacramento do Rio da Prata, códice 677, da Biblioteca Nacional de Lisboa. (Dissertação de Mestrado) - São Paulo, USP, 2008; POSSAMAI, Paulo César. De núcleo de povoamento à praça de guerra: a Colônia do Sacramento de 1735 a 1777. Topoi, v. 11, n. 21, p. 23-36, jul./dez. 2010.
} 
bélica da Nova Colônia do Sacramento do Rio da Prata, códice 677, da Biblioteca Nacional de Lisboa".

No capítulo final da monografia trabalho a análise da crônica propriamente dita, no campo do discurso e da retórica construída por Simão Pereira de Sá. A obra, que fora encomendada por Gomes Freire de Andrade, tinha em sua escrita um claro tom de convencimento à luta pela posse da Colônia do Sacramento por parte dos portugueses. A exaltação das qualidades - mais do que somente do povo que ali vivia -, mas também da praça em si, demonstra a intenção de Pereira de Sá em provar o valor daquela terra e a importância de mantê-la sob domínio luso, mesmo sendo onerosa financeiramente a constante luta contra os castelhanos pela posse da praça.

Embora eu não tenha conhecimento de documentos que possam provar minhas conclusões, acredito que a obra de Simão Pereira de Sá teve certo impacto no convencimento no seu auditório pretendido - como o Conselho Ultramarino e os conselheiros do Rei - do valor da Colônia do Sacramento, pois Portugal manteve seu interesse pela mesma até 1777, quando abriu mão de maneira definitiva da mesma aos castelhanos no Tratado de Santo Ildefonso, para recuperar o vasto território perdido aos espanhóis entre 1763 e 1777.

A habilidade retórica de Simão Pereira de Sá é de tal maneira expressiva e competente que mesmo hoje vemos autores sendo seduzidos pelas palavras de convencimento deste. Na historiografia contemporânea vemos a retomada do valor da Colônia do Sacramento 
através das palavras de Simão Pereira de Sá, onde se rompe com o modelo nacionalista-tradicionalista que desprezava a Colônia e passa-se a compreender Sacramento e sua importância dentro do contexto do Império Português no século XVIII.

\section{Referências}

ABREU, Capistrano de. Capítulos da História Colonial: 1500 - 1800. Brasília: Conselho Editorial do Senado Federal, 1998. Disponível em: http://www.dominiopublico.gov.br/pesquisa/DetalheObraForm.do?selec t_action=\&co_obra $=2074$

DOMINGUES, Moacyr. A Colônia do Sacramento e o sul do Brasil. Porto Alegre: Sulina, 1973.

HAMEISTER, Martha Daisson. O continente do Rio Grande de São Pedro: os homens, suas redes de relação e suas mercadorias semoventes (c. 1727-c. 1763). (Dissertação de Mestrado) - Rio de Janeiro, UFRJ, 2002. Disponível em:

http://www.dominiopublico.gov.br/pesquisa/DetalheObraForm.do?selec t_action=\&co_obra=18909

. No princípio era o caos: a formação de um povoado na fronteira americana dos Impérios Ibéricos através do estudo das relações de compadrio. Revista de História Regional, v. 15, 2010. Disponível em:

http://www.revistas2.uepg.br/index.php/rhr/article/viewFile/2374/1869

MARQUES, Viviane Sueli. Edição semidiplomática de História topográfica e bélica da Nova Colônia do Sacramento do Rio da Prata, códice 677, da Biblioteca Nacional de Lisboa. (Dissertação de Mestrado) - São Paulo, USP, 2008. Disponível em: http://www.teses.usp.br/teses/disponiveis/8/8142/tde-25112009110609/pt-br.php 
PERELMAN, Chain, OLBRECHTS-TYTECA, Lucie. Tratado de argumentação: a nova retórica. 2. ed. Tradução Maria Ermantina de Almeida Prado Galvão. Revisão da tradução Eduardo Brandão. São Paulo: Martins Fontes, 2005. (Justiça e direito).

PRADO, Fabrício. Colônia do Sacramento: O Extremo Sul da América Portuguesa. Porto Alegre: Editora Prefeitura Municipal de Porto Alegre, 2002.

SÁ, Simão Pereira de. Historia Topografica e Belica da Nova Colonia do Sacramento do Rio da Prata, Escrita por Ordem do Governador e Capitão Geral do Rio de Janeiro em 1737 e 1777. Porto Alegre: Arcano 17, 1993.

SPALDING, Walter. Gênese do Brasil-Sul. Porto Alegre: Livraria Sulina Editora, 1953.

Livraria Sulina Editora, 1969.

. Construtores do Rio Grande. v. 1. Porto Alegre:

. Construtores do Rio Grande. v. 2. Porto Alegre:

Livraria Sulina Editora, 1969.

. Construtores do Rio Grande. v. 3. Porto Alegre:

Livraria Sulina Editora, 1973.

VELLINHO, Moysés. Fronteira. Porto Alegre: Editora Globo, 1975.

Recebido em 24/11/2015, aceito para publicação em 06/12/2015. 